NBER WORKING PAPER SERIES

\title{
THE WAGE EFFECTS OF NOT-FOR-PROFIT AND FOR-PROFIT CERTIFICATIONS: BETTER DATA, SOMEWHAT DIFFERENT RESULTS
}

\author{
Kevin Lang \\ Russell Weinstein \\ Working Paper 19135 \\ http://www.nber.org/papers/w19135 \\ NATIONAL BUREAU OF ECONOMIC RESEARCH \\ 1050 Massachusetts Avenue \\ Cambridge, MA 02138 \\ June 2013
}

This topic was brought to our attention by Jesse Felix whose excellent undergraduate research opportunities project was, to the best of our knowledge, the earliest use of the Beginning Post-Secondary Students survey to examine differences in financial and labor market outcomes of students at for-profit and other institutions. We regret that data access restrictions prevented him from working with us on this new project. We are grateful to Steve Erlebacher and participants in the Boston University empirical microeconomics workshop for helpful comments and suggestions. The usual caveat applies. The views expressed herein are those of the authors and do not necessarily reflect the views of the National Bureau of Economic Research.

NBER working papers are circulated for discussion and comment purposes. They have not been peerreviewed or been subject to the review by the NBER Board of Directors that accompanies official NBER publications.

(C) 2013 by Kevin Lang and Russell Weinstein. All rights reserved. Short sections of text, not to exceed two paragraphs, may be quoted without explicit permission provided that full credit, including $\odot$ notice, is given to the source. 
The Wage Effects of Not-for-Profit and For-Profit Certifications: Better Data, Somewhat Different Results

Kevin Lang and Russell Weinstein

NBER Working Paper No. 19135

June 2013

JEL No. I23,J3

\begin{abstract}
Using the Beginning Postsecondary Student Survey and Transcript Data, we find no statistically significant differential return to certificate or Associate's degrees between for-profits and not-for-profits. Point estimates suggest a slightly lower return to a for-profit certificate and a slightly higher return to a for-profit Associate's degree, largely because more students at not-for-profits earn a BA, making them less likely to have only an Associate's degree. There is considerable variation in the return to certificates/degrees across majors, including many with negligible or negative returns. Differences across fields are large relative to differences across institution types.
\end{abstract}

\author{
Kevin Lang \\ Department of Economics \\ Boston University \\ 270 Bay State Road \\ Boston, MA 02215 \\ and NBER \\ lang@bu.edu \\ Russell Weinstein \\ Department of Economics \\ Boston University \\ 270 Bay State Rd \\ Boston, MA 02215 \\ weinst@bu.edu
}




\section{Introduction}

Critics of for-profit universities charge that these institutions recruit unqualified students in order to obtain their federal student aid and provide these students with little benefit. Indeed, in 2009, students at for-profit institutions accounted for nearly half of student loan defaults (US Department of Education, 2012a), but only about 11 percent of post-secondary students (US Department of Education, 2011a). Total funding received by for-profit post-secondary institutions under Title IV in 2010-2011 was more than 32 billion dollars, about $20 \%$ of total Title IV funds (US Department of Education, 2012b, US Department of Education, 2011b). Proponents, in contrast, argue that for-profit institutions educate non-traditional students who would not otherwise attend college and who therefore benefit from their existence. They maintain that the large quantity of loans and defaults reflects the efforts of for-profit institutions to serve this under-served group. ${ }^{1}$

Using a rich data set, we investigate whether there is a differential labor market return to certification from for-profit institutions. ${ }^{2}$ Estimating differential returns is challenging. Since students who enter for-profit institutions tend to be disadvantaged, their poorer labor

\footnotetext{
${ }^{1}$ The principal difference between for-profit and not-for-profit organizations is that not-for-profit firms cannot distribute profits to those who exercise control over the firm (Hansmann, 1996) but must distribute them in other ways, such as improving buildings and classrooms or by avoiding profits through lower prices. In the United States, not-for-profit educational institutions are generally exempt from corporate and property taxation, donations are tax deductible for the donor, and they have access to tax-exempt bond financing. However, for-profit institutions can use equity financing. Glaeser and Shleifer (2001) develop a model of why firms choose non-profit status that does not focus on the tax benefits, but rather on the firm's desire to constrain their ability to maximize profits. This improves their competitive standing in markets where firms are able to take advantage of their customers. A related literature on for-profit and not-for-profit hospitals finds no clear difference in quality (McClellan and Staiger, 2000). In theory, for-profit institutions have greater incentives to provide lower quality care in the absence of perfect information which could lead consumers to pay a premium to stay in a not-for-profit hospital, but this prediction is not confirmed in the data (Philipson, 2000).

${ }^{2}$ In this paper, not-for-profit institutions include both public institutions and private, not-for-profit institutions.
} 
market performance after completing their education may reflect our inability to control adequately for pre-entry differences. Therefore we compare the difference in earnings between certification completers and non-completers across institution types. If the difference in earnings between certification completers and non-completers is similar across institution type, lower wages of for-profit certification completers are more likely to be explained by pre-entry differences than by institution type. If the wages of certification completers relative to non-completers are lower at for-profit institutions, this suggests lower returns to for-profit certifications. This conclusion requires that any ability (or other) bias affecting the measured return to certification be similar across institution type. To further account for pre-entry differences in background, we present propensity-score-weighted regressions.

We find no statistically significant differential return to certification from for-profit institutions. However, the point estimate of the differential return is non-trivially negative for a for-profit certificate and non-trivially positive for a for-profit Associate's degree. Much of the latter difference reflects the greater tendency of strong students at not-for-profits to continue to a BA, leading to differential selection into the Associate's-degree-only group.

Controlling for major does not eliminate these differences. Nonetheless, the variation across major in the return to certifications is large relative to the for-profit/not-for-profit differential. The return to certificates in business and health fields (except Licensed Practical Nursing) is small or negative, while the return to a certificate in vocational fields is positive. In contrast, the return to an Associate's degree in business and health fields is very large, while small or negative in vocational fields and liberal arts and sciences.

The for-profit differential is identified mainly through majors with many students at both institution types. The possibly higher return to an Associate's degree from a for-profit than 
from a not-for-profit, therefore applies only to majors served by both sectors. Many notfor-profit majors are concentrated in Registered Nursing, a very high pay-off major that is nearly absent from for-profit colleges in our data.

Further, students starting Associate's degrees at not-for-profits are more likely to pursue a Bachelor's degree. If the best students go on to Bachelor's programs, the top of the skill distribution will be missing from the not-for-profit Associate's degree estimates. These students will either be classified as having a BA or missing from the data if they are still enrolled.

There is a small literature analyzing the for-profit post-secondary education sector. This paper is an updated version of Lang and Weinstein (2012), which utilized the survey but not the transcript data from the Beginning Post-Secondary Student Survey. The transcript data differ considerably from the survey responses and provide more detail about majors.

Using the NLSY97, Cellini and Chaudhary (2012) find some evidence that the returns to an Associate's degree from a for-profit are higher than those from a public institution. They do not consider certificates, an important educational offering at for-profit post-secondary institutions. In our sample, more than $60 \%$ of students enrolled at for-profit institutions are in certificate programs. Chung (2008) uses NELS88 which has a sample of only 157 respondents enrolled in either certificate or Associate's degree programs at for-profit colleges. She finds that, after controlling for selection, obtaining a for-profit certificate results in 141 to $158 \%$ higher earnings compared to those who have selected into the for-profit sector but do not complete any certification. Using administrative data, Turner (2011) finds a larger earnings increase after enrollment in two or four year not-for-profit institutions compared to for-profit institutions. However, the data are limited to enrollment and do not contain 
information on certification.

Deming, Goldin and Katz (2012) find that comparable students who enroll at for-profits are more indebted but more likely to obtain some qualification, most notably certificates and, more modestly, Associate's degrees, although less likely to obtain a Bachelor's degree. They have lower average earnings in part due to lower employment rates. Their paper is deliberately exploratory and does not attempt to address in-depth how differences in unemployment and school enrollment rates influence the estimated earnings differentials. Further, they consider returns to enrollment, and not to certification.

The paper proceeds as follows: Section 2 discusses the methods. Section 3 describes the data. Section 4 contains the results. Section 5 presents robustness checks, and Section 6 concludes.

\section{Methods}

Our data, discussed in detail below, consist of students who first enter post-secondary education in 2003-04. We generate separate estimates for those starting in certificate and Associate's degree programs since these groups are likely to be very different. We do not distinguish among individuals based on the types of programs the institution offers. Thus we pool individuals enrolled in, for example, certificate programs at two-year and four-year institutions. We do not examine students starting in non-certification or BA programs. For ease of presentation, in this section we drop notation distinguishing whether the sample is those entering certificate or Associate's degree programs. We use the term certification to refer to certificates, Associate's degrees, or Bachelor's degrees. 


\subsection{Basic Regression Analysis}

\subsubsection{Regressions without Controls for Major}

Our starting point is a fairly standard log-earnings equation, in which we do not control for the individual's major:

$$
\begin{aligned}
y= & \alpha+\beta_{1} F P+\beta_{2} C+\beta_{3} A+\beta_{4} B A+\beta_{5} C_{F P}+\beta_{6} A_{F P}+ \\
& +\beta_{7} B A_{F P}+X_{1} \beta_{8}+\eta
\end{aligned}
$$

where $y$ denotes log annual income in 2009. We have dropped the $i$ subscript for simplicity. The variable $C$ is an indicator for whether the highest certification obtained was a certificate, and similarly for $A$ (ssociate's) and $B A$ (chelor's). The variable $F P$ is an indicator for whether the student started at a for-profit, and the subscript FP denotes that the certificate or degree was obtained from a for-profit. Note that an individual who enters, for example, a certificate program in fall 2003 may have no certification, a certificate (but no higher certification), an Associate's degree or, very rarely, a BA in 2009.

$\beta_{2}$ through $\beta_{4}$ capture the "return" to earning certification at a not-for-profit while $\beta_{5}$ through $\beta_{7}$ capture the difference between this return and the return at a for-profit institution. We use the term "return" loosely to refer to the percentage difference in earnings between an individual who obtains a certification and one who started but did not obtain a certification. Thus, this use of return does not account for costs.

Because we are focused on the return to certifications, we do not additionally control 
for the highest certification program in which the respondent is ever enrolled. Individuals who enroll in a certification program sometimes enroll in a higher certification program after completing or, more rarely, without completing their original certification. To avoid cutting the data too finely, we control only for higher certifications that are completed and not those merely attempted.

Ability bias is a concern when estimating returns to education. Usually ability bias reflects the difference between those who do and do not obtain a certification or an extra year of education. In our case, ability bias reflects the unobserved difference in ability between those finishing and those starting but not finishing at a particular type of institution. If those who attempt post-secondary education but do not complete it are more favorably selected than those who never attempt it, ability bias is less problematic for our analysis.

Moreover, $\beta_{5}$ through $\beta_{7}$ can be interpreted as differences-in-differences estimates. Therefore, we require only that any ability bias be similar across institution types. More formally, write

$$
y=Z \Gamma+\beta_{2} C+\beta_{5} C_{F P}+W+U
$$

where we have combined the remaining variables into $Z$, and $W$ and $U$ represent the unobserved factors that are correlated and uncorrelated with the included explanatory variables. Our key parameter, $\beta_{5}$, will be unbiased if

$$
E\left(C^{\prime} W \mid Z, F P=1\right)=E\left(C^{\prime} W \mid Z, F P=0\right) .
$$

If ability bias is the same at for-profit and not-for-profit institutions, it will be removed when 
we compare the return at for-profit institutions to not-for-profit institutions. We discuss the plausibility of this assumption when we describe the data and also in the robustness section.

$\beta_{1}$ represents the return to starting a certificate or degree at a for-profit relative to a notfor-profit, for those who do not receive any certification. This coefficient can differ from zero either because human capital acquisition differs across institution types even among those who do not complete a certification, or because the types of students who do not complete any certification differ across institution types. To address the former explanation, in some specifications we control for time spent in post-secondary education and its interaction with $F P$.

$X_{1}$ denotes the explanatory variables that are determined before or just after enrollment, and therefore unlikely to be caused by the starting-institution type. These include age, household size (parental household size for dependent students, and respondent household size for independent students), income in 2002 (parental income for dependent students and respondent income for independent students), number of dependent children in 2003, and indicators for black, Hispanic, male, English is the primary language, married in 2003, and born in the United States. The explanatory variables also include family background characteristics: expected family contribution to college finances in 2003, and indicators for parents having at most 12 years of education, respondent claimed as a dependent in 2003, and both parents born in the United States. We also include academic variables: number of years the individual delayed enrollment in college after high school, whether attained a high school diploma, and whether obtained a GED. For those who began their post-secondary schooling before age 24, we also have indicators for high school GPA above 3.0, took the SAT or ACT, and SAT/ACT score. We refer to this last set as the under-24 variables. 
There are a number of potentially endogenous variables. These include the total amount of grants and veterans benefits for college the individual received in 2003, whether the individual was always a full-time student during his/her postsecondary schooling, GPA in 2003/2004, number of dependent children in 2006 and 2009, married in 2009, the number of times the student transferred, the number of months since the individual was last enrolled in college, and total months enrolled. The last two variables are measures of education quantity and post-education experience but may also be influenced by institution choice. Our preliminary investigations showed only minor differences from our main results when we included the post-2003 characteristics. We therefore present results only with the clearly exogenous explanatory variables except for some robustness checks.

As noted above, some potentially important variables are available only for those starting post-secondary education before age 24 . We therefore choose four different combinations of sample and explanatory variables: a "young" sample with all variables, a young sample with only variables available for the entire sample, an "old" sample, and the full sample. For the young sample, a specification test never rejects that our baseline estimates of the effects of certification are unaffected by including the under-24 variables. Moreover, we cannot reject the hypothesis that the coefficients are the same for the young and old samples for those starting in Associate's degree programs. While we do reject this null for those starting in certificate programs, the coefficients of interest do not differ between the two samples. We thus estimate a regression interacting every variable with an indicator for being in the older sample, except for these coefficients of interest. Including these interactions does not noticeably change the interpretation of the results.

For ease of presentation, we focus on the results from the regressions without these 
interactions. We present the main specification estimates for the young sample with the under-24 variables, the old sample, and for the full sample. For all remaining specifications, we present only the results for the full sample, which are also generally the most precise. However, in the text we point out any notable differences among samples and specifications.

\subsubsection{Regressions Controlling for Major}

Returns may differ among institutions because the fields they cover have different returns. Therefore, we augment equation (1) with indicators for major of highest certification or highest certification program for non-completers. These are business, manual and technological vocational training, liberal arts and sciences, human services, registered nursing, licensed practical/vocational nursing, health administration, allied health-assisting, allied health-treatment, somatic bodywork and related therapeutic services, health preparatory programs, other health majors, health (survey), ${ }^{3}$ and undeclared. These comprise the full set of majors in the data.

To allow major to affect labor market returns, we then further augment this equation by interacting major with highest certification. However, due to limited data we combine some of the majors: ${ }^{4}$

\footnotetext{
${ }^{3}$ As will be explained in the data section, this refers to the broad field of health, and is used only for those without transcript data on major.

${ }^{4}$ Some individuals have more than one highest degree. If the majors for these highest degrees differ, there will be more than one major. To not impose the restriction that having two highest degrees is twice as valuable as one, we control for (TotalHighestCertificate-1), and this variable interacted with the degrees being from a for-profit. We create analagous variables for Associate's degrees and Bachelor's degrees. However, these variables are not jointly significant and have little effect on the variables of interest, and so we do not include them in the specifications shown here.
} 


$$
\begin{aligned}
& y=\alpha+\beta_{1} F P+ \\
& \sum_{m \in \text { major }}\left[\zeta_{m} C_{m}+\gamma_{m} A_{m}+\delta_{m} B A_{m}\right]+\beta_{2} C_{F P}+\beta_{3} A_{F P}+\beta_{4} B A_{F P} \\
& +X_{1} \beta_{5}+\beta_{6} \text { healthfield }+\beta_{7} \text { business }+\beta_{8} \text { vocational }+\beta_{9} \text { healthsurvey } \\
& \quad+\beta_{10} \text { artssciences }+\beta_{11} \text { humanservices }+\beta_{12} \text { undeclared }+\eta
\end{aligned}
$$

The variable healthfield is an indicator for majoring in one of the eight health fields defined from the transcript data (registered nursing; licensed practical/vocational nursing; health administration; allied health-assisting; allied health-treatment; somatic bodywork and related therapeutic services; health preparatory programs; other health majors). The variable $C_{m}$ is an indicator for the highest certification being a certificate, and the major associated with that certificate being $m$; similarly for $A_{m}$, and $B A_{m}$.

We interpret the coefficients on $C_{m}$ as the return to a not-for-profit certificate in major $m$ relative to starting, but not completing a certificate with this major at a not-for-profit. ${ }^{5}$ However, if $m$ is one of the eight health majors from the transcript, $C_{m}$ is the return to certification with major $m$ relative to someone who started, but did not complete certification and majored in any of the health fields. This can be seen in specification (4) in that we control only for health field as described above and do not include eight separate health field intercepts because the number of individuals who start, but do not complete a program in each individual health field is too small. The coefficients on $A_{m}$ have the same interpretation

\footnotetext{
${ }^{5}$ If the major is missing in the transcript data, we instead use the most recent major as given in the survey response.
} 
mutatis mutandis.

The coefficient on $C_{F P}$ denotes the differential return to a certificate from a for-profit, relative to a certificate from a not-for-profit, holding major constant. $A_{F P}$ and $B A_{F P}$ have similar interpretations.

\subsection{Propensity Score Weighting}

Since we will see that students beginning at different institution types have quite different background characteristics, and since the linearity assumptions underlying the regression model may be problematic, as a robustness check we use propensity-score weighting. We use standard logit to calculate the propensity to start at a for-profit institution separately for the under-24 sample with the under-24 only variables; the under-24 sample without the under-24 only variables, and the 24 and above sample. In the regressions using the full sample, the propensity score weights for individuals less than 24 are those that were calculated for the under-24 sample with the under-24 only variables, and the weights for individuals 24 and older are those that were calculated for that sample. Once we have calculated the probability that an individual started in a certificate (Associate's degree) program at a for-profit college, these probabilities are used to generate weights in the usual way. In the following sections, we present results obtained from estimating regressions with the observations weighted by the sample weights multiplied by these propensity score weights. The details of the propensity score methods are included in the appendix. 


\section{Data}

We use the Beginning Post-Secondary Student Survey and Transcript Data, 2004 (hereafter BPS) sponsored by the US Department of Education. The BPS is a sample of approximately $16,680^{6}$ students who began post-secondary education for the first time in the 2003-2004 academic year. Students were surveyed in their 1st, 3rd, and 6th year after entering college. Since the BPS sample is first-time college students, it contains individuals who are enrolled both continuously and non-continuously. This is beneficial for our study since students in certificate and Associate's degree programs are often non-traditional college students, and may have non-continuous enrollment patterns. However, the BPS will be unrepresentative if many certifications are awarded to students who take more than six years to complete the program.

For each individual in the BPS, transcripts were collected from each institution attended from July 2003 to June 2009. The transcript data contain detailed information on degree program, major, degrees obtained, and grades. Because many students who enter four-year programs do not complete within six years, we focus on a sample of close to 1370 students who entered certificate programs and 1900 who entered Associate's degree programs. All institutions in the data have signed Title IV agreements with the Department of Education. This means they are accredited by at least one Department of Education approved accrediting agency and thus are eligible for Title IV aid.

Many of the variables of interest are available through both the survey and transcript data. For example, respondents are asked about the degree program in which they start, their

\footnotetext{
${ }^{6}$ For confidentiality reasons, the Department of Education requires that reports of observations be rounded to the nearest ten.
} 
highest degree, and the sector of the institutions they attended. However, this information is also on the transcripts provided directly by the educational institutions. There are significant differences between the survey responses and the transcript data. We treat the transcripts as more accurate, and so define the variables using the transcript data when both are available. Only for the small percentage of individuals without transcripts or with missing data on the transcripts, do we use survey responses for variables also covered in the transcript data.

As described in the methods section, we control for major of highest certification earned, or highest program for non-completers. If an individual has two certifications at the same level and none higher, she will have two majors if they are from the same type of institution. For this reason there is no omitted major category. We drop the few individuals with one certification from a for-profit and one from a not-for-profit because it is impossible to discern which certification is more responsible for labor market outcomes.

The survey response does not distinguish among health fields. The variable "healthsurvey" equals one if the individual does not have transcript data on major and reports his major as health.

Unfortunately, labor market data for 2009 were collected only for those whose last date of enrollment was before February 2009. Our baseline results thus drop students who were still enrolled five and a half years after entering a certificate or Associate's degree program. However, we perform a number of robustness checks to address these missing data.

Table 1 summarizes the data. The first two columns are the certificate program sample, separated by those starting at a for-profit (680 observations) and not-for-profit (690 observations). The last two columns describe the Associate's degree sample which is dominated by those starting at not-for-profit programs (1520 observations) relative to those starting 
at for-profit programs (380 observations). The means are calculated using the sampling weights.

\subsection{Certificate programs}

Table 1 shows that income in 2009 is approximately $\$ 6500$ lower for students starting certificate programs at for-profit institutions than for those starting certificate programs at not-for-profit institutions, statistically significant at the .01 level. It is by no means evident, however, that this difference is causal. Compared to those who start at not-for-profit institutions, students starting in certificate programs at for-profit institutions are much more likely

to be black, Hispanic, female, younger, single, and listed as a dependent at the time they enter college. Furthermore, income in 2002 (parental for dependent students and respondent for independent students) and expected family contribution to college are much lower. They are also less likely to have taken the SAT. Somewhat more of those entering not-forprofits (44\%) than of those entering for-profits (34\%) have not gained any certification. This difference is statistically significant at the .05 level.

\subsection{Associate's degree programs}

Table 1 shows that income in 2009 for students starting Associate's degree programs at for-profit institutions is approximately $\$ 3000$ less than for those starting at not-for-profit programs, statistically significant at the .05 level. Again, it is not clear that this difference is causal. Compared to those who start at not-for-profit institutions, students starting in Associate's degree programs at for-profit institutions are much more likely to be Hispanic and 
single, and less likely to be listed as a dependent at the time they enter college. Furthermore, income in 2002 (parental for dependent students and respondent for independent students) is much lower among for-profit students, their parents are less likely to have more than 12 years of schooling and are less likely to be born in the US, and their expected family contribution to college is much lower. Students starting at for-profits are less likely to have obtained their high school diploma, and more likely to have obtained their GED. They are also less likely to have taken the SAT.

Unfortunately, the pattern of certification differs between those entering Associate's degree programs in for-profits and not-for-profits. In both cases there are small, not significantly different, numbers of students reporting leaving with a certificate as their highest degree (between 2 and $3 \%$ at both institution types) and also who have acquired no certification ( $51 \%$ at both institution types). However, those starting in Associate's degree programs at not-for-profit institutions are much more likely to have obtained a Bachelor's degree (and less likely to have obtained only an Associate's degree) than are those who started at a for-profit institution. Therefore, those with only an Associate's degree are likely to be more favorably selected if they began at a for-profit. This differential ability bias could bias the differences-in-differences estimates of the differential return to certification. We present some evidence on the extent of differential ability bias across institution type in the robustness section. 


\subsection{Differences in major across institution type}

Table 2 shows sample size by major for those obtaining and those starting but not completing certifications. Panel A shows striking differences between the two types of institutions. Those obtaining not-for-profit certificates are much more likely to major in business, vocational fields, and licensed practical/vocational nursing than are those obtaining for-profit certificates. They are less likely to major in human services, allied health-assisting, and health administration.

Panel B shows this information for those starting Associate's degree programs. We see similar differences between institution types. Compared with individuals obtaining for-profit Associate's degrees, those obtaining not-for-profit Associate's degrees are much more likely to major in liberal arts and sciences and registered nursing and much less likely to major in vocational fields and allied health-assisting. Similar proportions of students major in business, human services, and allied health-treatment at the two types of institution.

Requirements for employment vary considerably across health fields. Medical assisting and health administration, representing 37 and 17 percent of certificates and Associate's degrees from for-profits but only 11 and 9 percent from not-for-profits, do not require licensing or degree completion (BLS, 2012). Licensed practical/vocational nursing (10 percent of notfor-profit and 1 percent of for-profit certificates) and registered nursing (10 percent of notfor-profit and almost no for-profit certificates), do require licensing and degree completion. Although simple theory suggests returns should be equalized, we would not be surprised if required certifications yield higher returns 


\section{Results}

\subsection{Return to Certificates for those Starting in Certificate Pro-}

grams

Panel A of table 3 shows the return to certificates, not controlling for major, for students who begin in a certificate program. Columns (1) and (4) show the results for the full sample using OLS and propensity score matching. The coefficient on Certificate is small, positive, and statistically insignificant in both specifications, suggesting no return to a certificate from a not-for-profit although the confidence interval includes nontrivial effects. The coefficient on Certificate $_{F P}$ in row (3) is non-trivial and negative in both specifications, suggesting a smaller return to a certificate from a for-profit than a not-for-profit, but the coefficient again falls short of statistical significance. Row (4) gives the sum of the coefficients on Certificate and Certificate $_{F P}$, which is about -5 log points in both specifications.

The coefficient on the indicator for starting at a for-profit is negative and non-trivial in both specifications and thus suggests that non-completers have lower incomes at for-profits than at not-for-profits. Unless dropouts differ in time spent enrolled or post-enrollment experience (both explored briefly below), we would expect dropouts from different institution types to have similar earnings if we control adequately for other differences. While the differences here are not statistically significant, they may suggest failure to control for some unobservables.

Thus, these estimates suggest a small return to a not-for-profit certificate, a negative differential to a for-profit certificate, and perhaps some evidence that even with our controls, 
those starting at for-profits are negatively selected. The results for the young and old samples are not dramatically different, although the coefficient on starting at a for-profit is more negative and the return to a certificate is larger for the younger sample.

Table 4 gives the results for the specifications controlling for major, using the sample of all ages. We focus on the full sample because the sample sizes by major get small when restricted to the young or old sample. Columns (1) and (4) are the same as Columns (1) and (4) in panel A of table 3, repeated to facilitate comparing results controlling and not controlling for major. Columns (2) and (5) control for major. The coefficient on Certificate falls in both specifications when majors are included. Further, the OLS coefficient on Certificate $F P$ falls slightly in magnitude while it is unchanged in the propensity score estimates. The total return to a certificate at a for-profit is more negative. Finally, the coefficient on starting at a for-profit decreases in magnitude when we control for major.

Finally, in columns (3) and (6) we show the results with interactions between major and certification. The coefficient on Certificate $_{F P}$ falls even more in magnitude using OLS but rises slightly using propensity score matching, so that the two methods generate similar results.

Rows (5) through (11) of the third and sixth columns reveal that there is considerable variation across majors in the return to certificates. While the interaction between each major and certification is included in the regression, we only present the returns to certificates for majors where at least 30 students obtained a certificate in the OLS sample. None of the returns is statistically significant, with the exception of a large, positive return to a certificate in vocational fields, and a large, negative return to a certificate in business (statistically significant in the propensity score specification). However, the return to certificates 
in Licensed Practical Nursing is large and positive. From table 2 we see LPNs are much more common at not-for-profit institutions and that non-completion is particularly high for business certificates. The F-statistic testing the joint significance of the major*certification interaction terms implies these terms are significant at the .01 level in both specifications, and similarly when we test the joint significance of these terms and the major intercepts. Finally, the F-test in both specifications rejects that the major*certification interaction terms are jointly equal, significant at the .01 level.

\subsection{Return to Degrees for those Starting in Associate's Degree Programs}

Panel B of table 3 shows the effect, not controlling for major, of certificates/degrees on students who begin in an Associate's degree program. Columns (1) and (4) show the results for the full sample using OLS and propensity score matching. The coefficient on Associatels in row 3, which denotes the return to an Associate's degree from a not-for-profit, is large, positive, and statistically significant and about 10 log points using both methods. The differential return to a for-profit Associate's degree, among those starting such degrees, is approximately $7 \log$ points using both estimates, though statistically significant in neither. The total return to an Associate's degree from a for-profit (the sum of the coefficients on Associatels and Associate $\left.s_{F P}\right)$ is large, positive, and statistically significant, with magnitude approximately 17 to $18 \log$ points in both specifications. Finally, the coefficient on the indicator for starting at a for-profit is negative and non-trivial in both specifications, and statistically significant in the propensity score specification. As suggested in the previous section, this may suggest 
failure to control for some unobservables.

We see large differences between the young and old samples among those starting in Associate's degree programs. The coefficient on Associatel $s_{F P}$ is approximately 21 log points larger for the old than the young sample, although not statistically significant. The coefficient on starting at a for-profit is also much more negative for the older sample, and statistically significant at the .1 level. This may suggest that the older sample is more negatively selected at for-profits than the younger sample is.

Table 5 presents the results for the specifications including controls for major. Columns (1) and (4) are the same as columns (1) and (4) in panel B of table 3 for reference. The return to a not-for-profit Associate's degree decreases in magnitude and statistical significance with the inclusion of controls for major in both columns (2) and (4). Further, the differential return to a for-profit Associate's degree decreases slightly and the return to an Associate's degree at a for-profit falls modestly.

Finally, in columns (3) and (6) we show the results from specification (2) which includes interactions between major and certification. The coefficient on Associatel $s_{F P}$ increases slightly in both cases, implying that those obtaining Associate's degrees from for-profits are in majors with slightly lower returns. After controlling for major, and major interacted with certification, we continue to see a non-trivial, although not statistically significant, positive differential effect of obtaining an Associate's degree from a for-profit relative to a not-for-profit.

Rows (9) through (15) in these columns give the returns to Associate's degrees in various fields. While the interaction between each major and certification is included in the regression, we only present the returns to Associate's degrees for majors where at least 30 
students obtained an Associate's degree in the OLS sample. It is clear that there is a lot of variation in the return to Associate's degrees across majors. We see large, positive returns, often statistically significant, to Associate's degrees in business, registered nursing, allied health-assisting, and allied health-treatment. The returns to an Associate's degree in liberal arts and sciences and vocational fields are very small and imprecise. We note that liberal arts and sciences is much more prevalent at not-for-profit institutions, while vocational majors are much more prevalent at for-profit institutions, as shown in table 2. The F-statistic testing the joint significance of the major*certification interaction terms implies these terms are significant at the .01 level in both specifications, and similarly when we test the joint significance of these terms and the major intercepts. Finally, the F-test in both specifications rejects that the major*certification interaction terms are jointly equal, significant at the .01 level.

Since students starting Associate's degrees at not-for-profits are more likely to advance to a Bachelor's degree, we now allow the "treatment" of starting at a not-for-profit to be holding at least an Associate's degree. This treats obtaining a Bachelor's degree as a causal effect of entering an Associate's degree program rather than as a nuisance variable for which we must control. We estimate specification (2) using this combined variable. The coefficient on AssocBach $_{F P}$ is less than half the size of Associatels $_{F P}$ in column (3) of table 5, with point estimate .032 and standard error .102 (not shown). This suggests that the "premium" for an Associate's degree from a for-profit is in part due to excluding the role of an Associate's degree at a not-for-profit as a pathway to a four-year degree. In assessing the near-zero coefficient when we combine two-year and four-year degrees, we should recognize that the latter take longer, but we should also recognize that students at not-for-profits are more likely 
to still be enrolled in a Bachelor's degree program and such students tend to be positively selected as measured by their GPA while in college (not shown). Our inability to include these students biases the coefficient on Associatel $_{F P}$ upward. ${ }^{7}$

\section{Robustness Checks}

In this section, we report the results of a series of robustness checks on the full sample.

\subsection{Differential Ability Bias}

Unbiased estimates of the differences-in-differences coefficients require that ability bias be similar across institution types. We addressed this in the Data section by comparing the distributions of certifications across institution types. In this section, we test for differential ability bias in two ways. First, we test for differences-in-differences in observables. If the observable differences between completers and non-completers are similar across institution type, this makes it more plausible that they are also similar in unobservables. Second, we estimate our main specifications without controls to see if the differences-in-differences coefficient changes, which is a way of summarizing the importance of observable differencesin-differences.

\footnotetext{
${ }^{7}$ Careful readers may note differences between the results in this paper and Lang and Weinstein (2012) attributable only to the use of the transcript data. They may wonder how using these data would affect the results in Deming, Goldin, and Katz (2011), hereafter DGK, who also use the Beginning Post-Secondary Student Survey. We have not explored this question in detail. Using the transcript data, we have reestimated the DGK specification, which gives the difference in earnings for those enrolling in a for-profit relative to a not-for-profit, controlling for observable background factors. For certificate programs, the coefficient on enrolling at a for-profit is -3211 , significant at the .05 level which contrasts with a statistically insignificant coefficient of -1576 in DGK. For those starting in Associate's degree programs, the coefficient on enrolling at a for-profit is -2382 and is not statistically significant, in contrast with a marginally significant coefficient of -2794 in DGK. Given the nature of that paper, these differences appear modest to us.
} 
We regress

$$
y=\alpha+\beta_{1} F P+\beta_{2} C+\beta_{3} A+\beta_{4} B A+\beta_{5} C_{F P}+\beta_{6} A_{F P}+\beta_{7} B A_{F P}+\epsilon
$$

The dependent variables are the variables in $X_{1}$. Since we have multiple tests, we use the Bonferroni correction adjusted for correlation. None of the differences-in-differences is statistically significant at the .05 level either for those starting in certificate or those starting in Associate's degree programs. This implies that the comparison of completers to noncompleters, in terms of observables, is similar across institution type.

When we estimate the principal specification without the explanatory variables, the differential return to a for-profit certificate, among those starting in certificate programs, is -.12 (standard error .1) without controls, relative to -.07 with controls (table 4, column (3)). Controlling for observable characteristics implies a somewhat smaller difference between forprofit and not-for-profit certificates, suggesting that the difference might be even smaller after accounting for differences in unobservables across institution types. The differential return to a for-profit Associate's degree, among those starting in Associate's degree programs, is .06 (standard error .1) without controls relative to .07 with controls (table 5, column (3)), suggesting little difference in observables.

Taken together these tests do not suggest large violations of the requirement that ability bias be similar for not-for-profit and for-profit institutions.

Wage is not observed for those who are either not employed or still enrolled in school. Differences across institutions in who is employed represent another possible source of bias. We showed earlier that those starting Associate's degree programs at for-profits are less likely 
to still be studying for a Bachelor's degree. The differential effect of certification from a forprofit, relative to a not-for-profit, on employment (conditional on no longer being enrolled) is statistically insignificant for both those starting certificates and Associate's degree programs (not shown). However, the magnitudes of the effects are nontrivial, suggesting that our estimates should be treated with caution.

\subsubsection{Time in program and time in labor market}

Certificate and Associate's degree programs may differ in length, and students might persevere longer in one type of institution than another. Because length of program, or length of time in program, may be correlated with human capital acquisition and thus earnings, we control for months enrolled (results not shown). For both those starting in Associate's degree and certificate programs, the coefficients on months enrolled are small and insignificant, and the remaining coefficients are unaffected.

Recall that the coefficient on Start at For-Profit is large and negative in table 4. To address further this somewhat troubling result, we include not only total months enrolled, but also its interaction with starting at a for-profit in specification (2). The coefficient on starting at a for-profit is therefore the effect of starting at a for-profit and not spending any time enrolled. Since we would not expect any differential for people spending no time enrolled, a negative coefficient would suggest failure to control for pre-entry differences. The coefficient on starting at a for-profit falls from -.108 in column (3) of table 5 to -.027 (not shown). The coefficient using propensity score weighting also falls but remains non-trivially negative. However, it falls further when we restrict the sample to those who were enrolled for at most 6 months (not shown). These results suggest that the large, negative coefficient 
on starting at a for-profit can be attributed to differences in time enrolled before dropping out and the differential benefit of incomplete programs across institution type, and not our failure to control for differences in entrants' characteristics.

Finally, we control for potential experience since leaving the program (measured by months since last enrolled). To allow for the possibility that wage growth after leaving school is higher or lower for those starting at for-profits, we include both a linear term for months since last enrolled and its interaction with starting at a for-profit. The results for our key coefficients are again very similar to those in the original specification (not shown).

\subsubsection{Labor Market Conditions}

The estimated returns might reflect differences in labor market strength in areas where for-profit and not-for-profit institutions are located. The median distance between the respondent's permanent home and starting-institution is 20 miles for individuals starting in for-profit and 14 miles for those starting in not-for-profit Associate's degree programs. The corresponding numbers are 15 and 10 miles for those starting in certificate programs. These distances suggest that for most students, the labor market where the post-secondary institution is located is a good proxy for the local labor market.

To investigate whether labor market strength is correlated with institution type, we include the unemployment rate for the county in which the institution is located, and this rate interacted with all of the certification*major interactions in specification (2). ${ }^{8}$

\footnotetext{
${ }^{8}$ We use the IPEDS data from 2003 because we are interested in the institutions at which the students started college, which is the 2003-2004 academic year. Some colleges that exist in 2003 do not exist in 2011. Since the IPEDS data from 2003 include the zip code of the institution but not the county code, we use the HUD crosswalk between zip code and county. We merge this with average county unemployment data for 2009 and assigned each institution its county unemployment rate. When one zip code maps to two or more counties, we calculate a weighted unemployment rate for the zip code. We use the institution where the
} 
The regressions including unemployment rate, and unemployment rate interacted with certification*major yield nearly identical results to those obtained with the same sample but without unemployment controls. While the coefficients on Certificate $_{F P}$ in table 4 and on Associatels $_{F P}$ in table 5 are larger in magnitude than those we obtain when we control for unemployment, this is largely due to the change in sample. Thus, our estimated returns do not appear to be biased by institutions of one type being located in particularly weak labor markets.

\section{Discussion and Conclusion}

The growth of the for-profit education sector in recent years has been dramatic, and its value has been widely debated. Much of this debate has involved claims that for-profit colleges leave students with very high debt levels and poor employment outcomes. Summary statistics presented in this paper indeed show that post-college income is significantly lower for students starting at for-profit institutions. However, it is also very clear that those who start at for-profit institutions are less well prepared for college, had lower levels of pre-college academic performance, and face other significant obstacles to college and post-college success. This paper controls for these characteristics using both traditional OLS and propensity score weighting.

individual was first surveyed, as defined in the transcript data. If this is unavailable, we use the institution where the individual obtained the highest degree, or the highest program for non-completers, as defined by the transcript data. If the transcript data are not available, we use the first institution at which the individual was surveyed, as defined in the survey data in 2006. Finally, if this information is unavailable, we use the first institution where the individual was surveyed, as defined in the survey data in 2009. Students are missing the unemployment rate either because the IPEDS identifier for their institution was missing, the zip code of the IPEDS identifier was not in the HUD crosswalk, or the IPEDS identifier was not found in the IPEDS data system (very few). 
We find large returns to Associate's degrees from both for-profit and not-for-profit institutions and some evidence of larger returns at for-profit institutions. However, we argue that much of the estimated difference across institution type in the return to an Associate's degree reflects the greater role of the Associate's degree as a pathway to a four-year degree at not-for-profit institutions. This leads individuals with only an Associate's degree and not enrolled in a Bachelor's degree program to be more adversely selected at not-for-profits.

In addition, we find only weak evidence overall that acquiring certificates raises wages. The evidence for certificates earned at for-profits is even weaker and the point estimate of this return is non-trivially negative. However, the return to for-profit certificates is not statistically significantly different than the return to not-for-profit certificates. Neither the for-profit Associate's degree premium nor the certificate discount disappears after controlling for field of study.

This conclusion comes with a number of caveats. First, some of the highest-return majors such as registered and licensed practical nursing are unrepresented at for-profits and therefore do not affect the comparison when we control for field of study. However, since the forprofit education industry has grown significantly, even since 2003 when our sample started post-secondary education, it is possible that for-profit institutions have begun to offer these higher-return majors.

Second, our income data are from 2009, during an economic recession. It is possible that the recession affected the return to certificates and Associate's degrees differently in different sectors. Furthermore, since for-profits and not-for-profits specialize in different majors, if the recession affected certain fields more than others, we would expect that to affect the differential return. 
Finally, our data only allow us to observe wages at most a few years after completing a certification; we can only estimate short-run labor market effects. The wages of individuals getting certifications from for-profits may subsequently grow faster or more slowly than those with certifications from not-for-profits.

In general, our results suggest that the percentage increase in earnings from for-profit and not-for-profit certifications are similar. However, students who enroll at for-profits start with a lower earnings base, and the cost of tuition at for-profit universities is much higher than at not-for-profit institutions. Using data from the BPS, in 2003, tuition and fees for those starting in for-profit certificate programs were about $\$ 6300$ more than for those starting in not-for-profit certificate programs (statistically significant at the .01 level). Similarly, the total was approximately $\$ 6900$ more for students starting for-profit relative to not-for-profit Associate's degree programs (statistically significant at the .01 level). Given these large differences, the return on investment is undoubtedly lower at for-profits.

Perhaps most significantly, this paper underscores the large differences across field in the labor market benefits of certificates and Associate's degrees, and the minimal benefits of certificates in many fields. As policy-makers consider their response to the explosion of student debt, they may want to consider programs within institutions rather than simply the overall performance of the institution.

\section{References}

[1] Becker, Sascha O. and A. Ichino. "Estimation of Average Treatment Effects Based on Propensity Scores." Stata Journal. Vol. 2, Number 4. 2002. 
[2] Bureau of Labor Statistics. "Occupational Outlook Handbook." www.bls.gov/ooh. Accessed December, 2012.

[3] Cellini, S. and L. Chaudhary. "The Labor Market Returns to a For-Profit College Education." NBER Working Paper 18343. August, 2012.

[4] Chung, A. "Effects of For-Profit College Training on Earnings." Working Paper. October, 2008.

[5] Crump, R., V.J. Hotz, G. Imbens, and O. Mitnik. "Dealing with Limited Overlap in Estimation of Average Treatment Effects" Biometrika. Vol. 96(1). 2009.

[6] Deming, D., C. Goldin, and L. Katz. "The For-Profit Postsecondary school sector: Nimble critters or Agile Predators?" NBER Working Paper 17710. 2011.

[7] Glaeser, E., A. Shleifer. "Not-for-Profit Entrepreneurs." Journal of Public Economics. Vol. 81. 2001.

[8] Hansmann, H. The Ownership of Enterprise. Harvard University Press. Cambridge, MA. 1996.

[9] Imbens, G. "Methods for Estimating Treatment Effects I: Unconfounded Treatment Assignment." Lecture at Impact Evaluation Network. 2010.

[10] Lang, K., and R. Weinstein. "Evaluating Student Outcomes at For-Profit Colleges." NBER Working Paper 18201. June, 2012.

[11] McClellan, M., and D. Staiger. "Comparing Hospital Quality at For-Profit and Not-forProfit Hospitals." In The Changing Hospital Industry: Comparing For-Profit and Notfor-Profit Institutions. Ed. D. Cutler. University of Chicago Press. p. 93-112. January, 2000.

[12] Philipson, T. "Asymmetric Information in the Not-for-Profit Sector: Does its Output Sell at a Premium?" In The Changing Hospital Industry: Comparing For-Profit and Not-for-Profit Institutions. Ed. D. Cutler. University of Chicago Press. January, 2000.

[13] Turner, Nicholas. "Do Students Profit from For-Profit Education? Estimating the Returns to Postsecondary Education with Tax Data." Unpublished manuscript. October, 2011.

[14] US Department of Education. Federal Student Aid Data Center. "Comparison of 2-Year Official National FY 2010 Cohort Default Rates to Prior Two Official Calculations." 2012a.

[15] US Department of Education. National Center for Education Statistics. Digest of Education Statistics. Table 196. 2011a.

[16] US Department of Education. Federal Student Aid Data Center. "Proprietary School 90/10 Revenue Percentages Report". Accessed 10/29/12. 2012b.

[17] US Department of Education. "Federal Student Aid Annual Report, 2011." 2011b. 


\section{A Appendix}

\section{A.1 Propensity Score Methods}

In order to calculate the propensity of an individual to start post-secondary education at a for-profit institution, we first used the algorithm proposed by Imbens (2010). As noted in the paper, we calculate propensity scores separately for the three samples/specifications described.

1. Estimate the standard logit model with all of the variables in $X_{1}$ including the under24-only variables in the specifications where they are included in the propensity score specification.

2. Estimate a standard logit model, with the regressors being the same as those in Step 1 , but each time include an additional interaction term between the linear terms in Step 1. Calculate the likelihood ratio test statistic.

3. If the likelihood ratio test statistic is greater than 2.71 , then include the interaction.

4. Now estimate a standard logit model, with the regressors being the linear terms in Step 1, and the interaction terms chosen in step 3, but each time include an additional interaction term which was not chosen. Calculate the likelihood ratio test statistic.

5. If the likelihood ratio test statistic is greater than 2.71 , then include the interaction.

6. The propensity score specification has been determined to be all of the linear terms in Step 1 and all of the interaction terms chosen in Steps 3 and 5.

For the younger sample, the algorithm finds that we should include the 23 linear terms, and 47 interaction terms for those starting in certificate programs and 100 interaction terms for those starting in Associate's degree programs. For the older sample, the algorithm finds that we should include the 20 linear terms and 35 interaction terms for those starting in certificate programs and 70 interaction terms for those starting in Associate's degree programs.

We employ the algorithm suggested by Crump, Hotz, Imbens, and Mitnik (2009) to trim the sample in order to address lack of overlap. In most cases, this results in discarding observations with propensity scores below approximately .1 and above approximately .9.

Once we have calculated the probability that an individual started in a certificate (Associate's degree) program at a for-profit college, those probabilities are used to generate weights. With i denoting the individual, and $\mathrm{j}$ denoting the type of institution at which the individual started (for-profit, not-for-profit), we weight the observations by

$$
\frac{\frac{1}{p_{i j}} N_{j}}{\sum_{i \in j} \frac{1}{p_{i j}}} \text { for } \mathrm{j}=\text { for-profit, and } \frac{\frac{1}{1-p_{i j}} N_{j}}{\sum_{i \in j} \frac{1}{1-p_{i j}}} \text { for } \mathrm{j}=\text { not-for-profit. } N_{j} \text { denotes the number of }
$$
observations starting in a certificate (Associate's degree) program at institution type $\mathrm{j}$, and

$p_{i j}$ denotes the propensity to start at a for-profit institution for individual $\mathrm{i}$ in institution type $\mathrm{j}$. The weights for each subgroup (start in a certificate (Associate's degree) program 
at a for-profit, not-for-profit institution) are such that the sum of the weights within the subgroup is the number of observations in that subgroup.

These weights are then used in the regression of income outcomes on whether the individual started at a for-profit college.

In order to check that the balancing property is satisfied for the propensity score (using the trimmed sample) we use an algorithm similar to that developed by Becker and Ichino (2002). We start by dividing the sample into five evenly spaced blocks of the propensity score. Then, within each interval, we check whether the average propensity score of those who start at for profit institutions differs from those who start at not for profit institutions, and if the average propensity score of those who start at for profit institutions differs from those who start at not-for-profit institutions. If the averages differ, then we split that block into two, and check if the averages differ in the new blocks. Once we have divided the sample into blocks such that within each block the average propensity score of the for-profit and not-for-profit groups is the same, we check whether the average value of each term in the propensity score specification differs between the for-profit and not-for-profit groups.

We use the standard Bonferroni correction for determining the threshold p-value for significance of each test since we have multiple tests of whether the average propensity score for each group differs within blocks. When we test whether the average of each variable differs within blocks, we use the Bonferroni correction adjusted for correlation across explanatory variables. Since we have many variables, and some of those variables are presumably correlated, a balancing test for one variable could provide information on the balancing test for another variable. The information from these correlations should be accounted for in the Bonferroni correction, raising the threshold p-value (lowering the critical t) relative to the traditional Bonferroni p-value used to determine significance for each test. In order to implement this strategy, we find the correlation between each of the variables used in the propensity score specification, and then take the mean of those correlations. The mean correlation is then used to adjust the standard Bonferroni correction. Since the propensity score specifications for the older and younger samples are different, we test the balance of the propensity score separately for these two samples. In the younger sample of those starting in certificate programs, this algorithm results in 5 blocks and no variables that are unbalanced, while in the older sample the algorithm results in 5 blocks and one variable out of 275 that is unbalanced. In the younger sample of those starting in Associate's degree programs, we obtain 7 blocks and 6 variables out of 861 that are unbalanced, while in the older sample the algorithm results in 5 blocks and no variables that are unbalanced.

\section{B Major Definition}

Majors are divided into 13 categories: business; liberal arts and sciences; vocational (manual and technical); human services; undeclared, and eight categories of health majors (registered nursing, licensed practical/vocational nursing, health administration, allied health-assisting, allied health-treatment, somatic bodywork and related therapeutic services, health preparatory programs, other health majors). If the major is not available from transcript data, we use the survey response, which does not distinguish between the various categories of health majors. We thus add an additional category, "healthsurvey", which equals one if the 
individual does not have transcript data on major and reports his as health. The CIP codes included in each definition are listed below

Business: CIP Codes

52 (Business, Management, Marketing, and Related Support Services)

Liberal Arts and Sciences: CIP codes

4 (Architecture and Related Services)

5 (Area, Ethnic, Cultural, Gender, and Group Studies)

14 (Engineering)

16 (Foreign Languages, Literatures, and Linguistics)

23 (English Language and Literature/Letters)

24 (Liberal Arts and Sciences, General Studies, and Humanities)

26 (Biological and Biomedical Sciences)

27 (Mathematics and Statistics)

30 (Multi/Interdisciplinary Studies)

38 (Philosophy and Religious Studies)

40 (Physical Sciences)

45 (Social Sciences)

50 (Visual and Performing Arts)

54 (History)

Vocational (Manual and Technical):

1 (Agriculture, Agriculture Operations, and Related Sciences)

3 (Natural Resources and Conservation)

15 (Engineering Technologies and Engineering-Related Fields)

29 (Military Technologies and Applied Sciences)

41 (Science Technologies/Technicians)

46 (Construction Trades)

47 (Mechanic and Repair Technologies/Technicians)

48 (Precision Production)

49 (Transportation and Materials Moving)

10 (Communications Technologies/Technicians and Support Services)

11 (Computer and Information Sciences and Support Services)

Human Services:

9(Communication, Journalism, and Related Programs)

12 (Personal and Culinary Services)

13 (Education)

19 (Family and Consumer Sciences/Human Sciences)

22 (Legal Professions and Studies)

25 (Library Science)

28 (Military Science, Leadership and Operational Art)

31 (Parks, Recreation, Leisure, and Fitness Studies)

39 (Theology and Religious Vocations) 
42 (Psychology)

43 (Homeland Security, Law Enforcement, Firefighting and Related Protective Services)

44 (Public Administration and Social Service Professions)

Registered Nursing: CIP Codes

51.38 (Registered Nursing, Nursing Administration, Nursing Research and Clinical Nursing)

Licensed Practical/Vocational Nursing: CIP Codes

51.39 (Practical Nursing, Vocational Nursing and Nursing Assistants)

Excluding 51.3902 (Nursing Assistant/Aide and Patient Care Assistant/Aide)

Health Administration: CIP Codes

51.07 (Health and Medical Administrative Services)

Allied Health-Assisting: CIP Codes

51.08 (Allied Health and Medical Assisting Services)

51.0601 (Dental Assisting/Assistant)

51.0699 (Dental Services and Allied Professions, Other)

51.1802 (Optometric Technician/Assistant)

51.1899 (Ophthalmic and Optometric Support Services and Allied Professions, Other)

51.3902 (Nursing Assistant/Aide and Patient Care Assistant/Aide)

51.1502 (Psychiatric/Mental Health Services Technician)

Allied Health-Treatment: CIP Codes

51.09 (Allied Health Diagnostic, Intervention, and Treatment Professions)

51.0602 (Dental Hygiene/Hygienist)

51.1801 (Opticianry/Ophthalmic Dispensing Optician)

51.1803 (Ophthalmic Technician/Technologist)

51.10 (Clinical/Medical Laboratory Science/Research and Allied Professions)

51.0603 (Dental Laboratory Technology/Technician)

51.2308 (Physical Therapy/Therapist)

51.2309 (Therapeutic Recreation/Recreational Therapy)

51.3103 (Dietetic Technician)

Somatic Bodywork: CIP Codes

51.3501 (Massage Therapy/Therapeutic Massage)

Health Preparatory Programs: CIP Codes

51.11 (Health/Medical Preparatory Programs)

Other Health Programs:

Programs with CIP Codes 51 (Health Professions and Related Programs) or 60 (Residency Programs), and not included in the above categories. 
Table 1: Summary Statistics by Initial Institution Type

\begin{tabular}{|c|c|c|c|c|}
\hline & $(1)$ & (2) & (3) & $(4)$ \\
\hline & \multicolumn{2}{|c|}{ Start Certificate Program } & \multicolumn{2}{|c|}{ Start Associates Program } \\
\hline & For-Profit & Not-For-Profit & For-Profit & Not-For-Prc \\
\hline \multicolumn{5}{|l|}{ Highest Degree } \\
\hline \multirow[t]{2}{*}{ Certificate } & 0.642 & $0.521^{* * *}$ & 0.03 & 0.022 \\
\hline & $(0.030)$ & $(0.030)$ & $(0.014)$ & $(0.006)$ \\
\hline \multirow[t]{2}{*}{ Associates } & 0.014 & 0.026 & 0.405 & $0.332^{*}$ \\
\hline & $(0.007)$ & $(0.007)$ & $(0.036)$ & $(0.018)$ \\
\hline \multirow[t]{2}{*}{ Bachelors } & 0.001 & $0.009^{*}$ & 0.052 & $0.133^{\star \star \star}$ \\
\hline & $(0.001)$ & $(0.004)$ & $(0.028)$ & $(0.012)$ \\
\hline \multirow[t]{2}{*}{ Months Since Last Enrolled } & 50.522 & $43.35^{\star \star \star}$ & 44.314 & $32.892^{\star \star \star}$ \\
\hline & $(0.905)$ & $(0.991)$ & $(1.284)$ & $(0.798)$ \\
\hline \multirow[t]{2}{*}{ Total Months Enrolled } & 13.678 & $20.068^{\star \star \star}$ & 20.615 & $28.078^{* * *}$ \\
\hline & $(0.411)$ & $(0.738)$ & $(1.147)$ & $(0.668)$ \\
\hline \multirow{2}{*}{$\begin{array}{l}\text { Expected Family Contribution, } \\
2003(\$, 000)\end{array}$} & 1.871 & $5.687^{\star \star \star}$ & 3.262 & $8.586^{\star * \star}$ \\
\hline & $(0.246)$ & $(0.454)$ & $(0.350)$ & $(0.569)$ \\
\hline \multirow{2}{*}{$\begin{array}{l}\text { Years Delayed Starting Post- } \\
\text { Secondary Education }\end{array}$} & 8.983 & 11.094 & 5.012 & 5.772 \\
\hline & $(1.737)$ & $(0.965)$ & $(0.548)$ & $(0.657)$ \\
\hline \multirow[t]{2}{*}{ High School Diploma } & 0.747 & 0.788 & 0.8 & $0.879^{* *}$ \\
\hline & $(0.027)$ & $(0.023)$ & $(0.033)$ & $(0.012)$ \\
\hline \multirow[t]{2}{*}{ GED } & 0.174 & 0.156 & 0.181 & $0.076^{\star \star \star}$ \\
\hline & $(0.022)$ & $(0.019)$ & $(0.033)$ & $(0.009)$ \\
\hline \multirow[t]{2}{*}{ English is Primary Language } & 0.856 & 0.889 & 0.883 & 0.911 \\
\hline & $(0.019)$ & $(0.020)$ & $(0.021)$ & $(0.010)$ \\
\hline \multirow{3}{*}{$\begin{array}{l}\text { Number of Dependent Children, } \\
2003\end{array}$} & & & & \\
\hline & 0.734 & 0.847 & 0.567 & 0.446 \\
\hline & $(0.061)$ & $(0.080)$ & $(0.067)$ & $(0.041)$ \\
\hline \multirow[t]{2}{*}{ Dependent, 2003} & 0.425 & $0.348^{*}$ & 0.451 & $0.649 * \star \star$ \\
\hline & $(0.030)$ & $(0.027)$ & $(0.037)$ & $(0.020)$ \\
\hline \multirow[t]{2}{*}{ Married, 2003} & 0.144 & $0.318^{\star \star \star}$ & 0.129 & $0.177^{*}$ \\
\hline & $(0.020)$ & $(0.031)$ & $(0.020)$ & $(0.017)$ \\
\hline \multirow[t]{2}{*}{ Age, 2003} & 24.163 & $29.126^{\star \star \star}$ & 23.69 & 23.744 \\
\hline & $(0.415)$ & $(0.731)$ & $(0.459)$ & $(0.433)$ \\
\hline \multirow[t]{2}{*}{ Male } & 0.254 & $0.438^{\star \star \star}$ & 0.45 & 0.429 \\
\hline & $(0.029)$ & $(0.031)$ & $(0.037)$ & $(0.020)$ \\
\hline \multirow[t]{2}{*}{ Hispanic } & 0.267 & $0.14^{\star \star *}$ & 0.212 & $0.137^{* *}$ \\
\hline & $(0.025)$ & $(0.024)$ & $(0.028)$ & $(0.014)$ \\
\hline \multirow[t]{2}{*}{ Black } & 0.335 & $0.156^{\star \star \star}$ & 0.2 & 0.149 \\
\hline & $(0.030)$ & $(0.020)$ & $(0.033)$ & $(0.014)$ \\
\hline \multirow[t]{2}{*}{ Income in $2002(\$, 000)$} & 23.409 & $38.625^{\star \star \star}$ & 28.815 & $50.698 * *$ \\
\hline & $(1.341)$ & $(1.671)$ & $(1.500)$ & $(1.830)$ \\
\hline \multirow[t]{2}{*}{ Born in the US } & 0.876 & 0.886 & 0.891 & 0.894 \\
\hline & $(0.017)$ & $(0.021)$ & $(0.029)$ & $(0.011)$ \\
\hline Parents Born in the US & 0.763 & 0.819 & 0.758 & $0.82^{\star}$ \\
\hline & $(0.024)$ & $(0.024)$ & $(0.034)$ & $(0.014)$ \\
\hline Household Size, 2003 & 3.207 & 3.36 & 3.059 & $3.638^{* * *}$ \\
\hline & $(0.090)$ & $(0.101)$ & $(0.101)$ & $(0.061)$ \\
\hline Parents' Ed $\leq 12$ & 0.636 & 0.578 & 0.528 & $0.436^{\star *}$ \\
\hline & $(0.030)$ & $(0.030)$ & $(0.039)$ & $(0.020)$ \\
\hline
\end{tabular}




\begin{tabular}{|c|c|c|c|c|}
\hline & (1) & (2) & (3) & (4) \\
\hline & \multicolumn{2}{|c|}{ Start Certificate Program } & \multicolumn{2}{|c|}{ Start Associates Program } \\
\hline & For-Profit & Not-For-Profit & For-Profit & Not-For-Profit \\
\hline \multicolumn{5}{|c|}{ Under-24-Only Regressors } \\
\hline \multirow[t]{2}{*}{ HS GPA > 3.0} & 0.558 & 0.634 & 0.651 & 0.63 \\
\hline & $(0.038)$ & $(0.038)$ & $(0.042)$ & $(0.023)$ \\
\hline \multirow[t]{2}{*}{ Took the SAT } & 0.33 & $0.584^{\star \star \star}$ & 0.537 & $0.755^{\star \star \star}$ \\
\hline & $(0.034)$ & $(0.040)$ & $(0.048)$ & $(0.019)$ \\
\hline \multirow[t]{2}{*}{ SAT/ACT score/100 } & 8.287 & 8.739 & 8.672 & 9.000 \\
\hline & $(0.216)$ & $(0.176)$ & $(0.255)$ & $(0.092)$ \\
\hline $\mathrm{N}$ & 400 & 340 & 250 & 1190 \\
\hline \multicolumn{5}{|l|}{ Outcome Variable } \\
\hline \multirow[t]{2}{*}{ Income, $2009(\$, 000)$} & 26.059 & $32.514^{\star \star \star}$ & 29.213 & $32.272^{\star \star}$ \\
\hline & $(0.856)$ & $(1.355)$ & $(1.276)$ & $(0.873)$ \\
\hline $\mathrm{N}$ & 680 & 690 & 380 & 1520 \\
\hline
\end{tabular}

Standard deviations in parentheses under the means. Observations are weighted by the sample weights from the survey. All variables are measured in 2009 , unless noted otherwise.

Stars next to values in Column 2 denote significant differences between Columns 1 and 2. Stars next to values in Column 4 denote significant differences between Columns 3 and 4.

Sample sizes are as shown, except for Parents'Ed $<=12$ as some individuals did not know their parents' education, and SAT/ACT score because some students did not take the exam.

${ }^{* * *} p<0.01,{ }^{* *} p<0.05,{ }^{*} p<0.1$ 
Table 2: Composition of Certification by Major, for Selected Majors

\begin{tabular}{|c|c|c|c|c|c|c|c|c|c|}
\hline Business & Vocational & $\begin{array}{l}\text { Liberal Arts } \\
\text { and Sciences }\end{array}$ & $\begin{array}{l}\text { Human } \\
\text { Services }\end{array}$ & $\mathrm{RN}$ & $\begin{array}{l}\text { Allied Health- } \\
\text { Assisting }\end{array}$ & $\begin{array}{l}\text { Allied Health- } \\
\text { Treatment }\end{array}$ & LPN & $\begin{array}{c}\text { Health } \\
\text { Administration }\end{array}$ & $\begin{array}{l}\text { Health } \\
\text { (survey) }\end{array}$ \\
\hline
\end{tabular}

Panel A: Start in Certificate Program

Not-For-Profit Certificates

For-Profit Certificates

No Degree

Panel B: Start in Associate's Degree Program

Not-For-Profit Associate's Degrees

For-Profit Associate's Degrees

No Degree

$\begin{array}{cc}14 \% & 35 \% \\ 4 \% & 14 \% \\ 12 \% & 18 \%\end{array}$

$17 \%$

$15 \% \quad 42 \%$

$20 \% \quad 16 \%$
5

$12 \%$
$24 \%$
$18 \%$

$\begin{array}{ccccc}8 \% & 10 \% & 3 \% & 5 \% & 340 \\ 26 \% & 1 \% & 11 \% & 8 \% & 450 \\ 12 \% & 6 \% & 4 \% & 7 \% & 540\end{array}$

Note: Each cell gives the percentage of observations with the type of certification in that row, with the major in that column. Major definitions are in Appendix.

a. denotes the percentage was omitted to preserve confidentiality of the few individuals in that cell. Percentages are only reported for majors where at least 30 people obtained certification (certificate in panel A, Associate's degree in panel B) with that major from either For-Profit or Not-for-Profit institutions. Health (survey) describes people who report a Health major in the survey, and do not have transcript data. 
Table 3: Impact of For Profit Colleges on Log Income, 2009: Without Controls for Major

\begin{tabular}{|c|c|c|c|c|c|c|c|}
\hline & & $\frac{(1)}{\text { All Ages }}$ & $\frac{(2)}{\text { Under } 24}$ & $\frac{(3)}{24 \text { and Over }}$ & $\frac{(4)}{\text { All Ages }}$ & $\frac{(5)}{\text { Under } 24}$ & $\frac{(6)}{24 \text { and Over }}$ \\
\hline & & \multicolumn{3}{|c|}{ OLS } & \multicolumn{3}{|c|}{ Propensity Score Weighting } \\
\hline \multicolumn{8}{|c|}{$\begin{array}{l}\text { Panel A: Start in Certificate Program } \\
\text { Start Program at: }\end{array}$} \\
\hline (1) & For-Profit & $\begin{array}{l}-0.048 \\
{[0.067]}\end{array}$ & $\begin{array}{c}-0.064 \\
{[0.086]}\end{array}$ & $\begin{array}{c}0.006 \\
{[0.092]}\end{array}$ & $\begin{array}{l}-0.067 \\
{[0.070]}\end{array}$ & $\begin{array}{l}-0.094 \\
{[0.085]}\end{array}$ & $\begin{array}{l}-0.007 \\
{[0.104]}\end{array}$ \\
\hline \multicolumn{8}{|c|}{ Highest Degree: } \\
\hline (2) & Certificate & $\begin{array}{c}0.043 \\
{[0.059]}\end{array}$ & $\begin{array}{c}0.114 \\
{[0.082]}\end{array}$ & $\begin{array}{c}0.042 \\
{[0.079]}\end{array}$ & $\begin{array}{c}0.012 \\
{[0.058]}\end{array}$ & $\begin{array}{c}0.069 \\
{[0.083]}\end{array}$ & $\begin{array}{c}0.024 \\
{[0.075]}\end{array}$ \\
\hline \multicolumn{8}{|c|}{ Certificate from: } \\
\hline (3) & For-Profit & $\begin{array}{l}-0.098 \\
{[0.090]}\end{array}$ & $\begin{array}{l}-0.146 \\
{[0.123]}\end{array}$ & $\begin{array}{l}-0.121 \\
{[0.116]}\end{array}$ & $\begin{array}{c}-0.062 \\
{[0.091]}\end{array}$ & $\begin{array}{l}-0.086 \\
{[0.119]}\end{array}$ & $\begin{array}{c}-0.114 \\
{[0.125]}\end{array}$ \\
\hline (4) & Combination (2) + (3) & $\begin{array}{l}-0.055 \\
{[.070]}\end{array}$ & $\begin{array}{l}-0.032 \\
{[.090]}\end{array}$ & $\begin{array}{l}-0.079 \\
{[.090]}\end{array}$ & $\begin{array}{l}-0.049 \\
{[.071]}\end{array}$ & $\begin{array}{l}-0.016 \\
{[.087]}\end{array}$ & $\begin{array}{l}-0.09 \\
{[.102]}\end{array}$ \\
\hline & $\mathrm{N}$ & 1370 & 740 & 630 & 1260 & 660 & 590 \\
\hline \multicolumn{8}{|c|}{$\begin{array}{l}\text { Panel B: Start in Associate's Degree Program } \\
\text { Start Program at: }\end{array}$} \\
\hline (1) & For-Profit & $\begin{array}{l}-0.123 \\
{[0.076]}\end{array}$ & $\begin{array}{l}-0.014 \\
{[0.062]}\end{array}$ & $\begin{array}{l}-0.301^{*} \\
{[0.166]}\end{array}$ & $\begin{array}{l}-0.149 * * \\
{[0.072]}\end{array}$ & $\begin{array}{l}-0.055 \\
{[0.066]}\end{array}$ & $\begin{array}{l}-0.297^{\star} \\
{[0.152]}\end{array}$ \\
\hline (2) & Certificate & $\begin{array}{l}0.295^{\star *} \\
{[0.120]}\end{array}$ & $\begin{array}{l}0.333^{*} \\
{[0.179]}\end{array}$ & $\begin{array}{l}0.356^{\star *} \\
{[0.138]}\end{array}$ & $\begin{array}{c}0.292^{\star \star \star} \\
{[0.096]}\end{array}$ & $\begin{array}{c}0.258^{\star * *} \\
{[0.084]}\end{array}$ & $\begin{array}{l}0.348^{\star *} \\
{[0.155]}\end{array}$ \\
\hline (3) & Associate's & $\begin{array}{l}0.110 * * \\
{[0.047]}\end{array}$ & $\begin{array}{c}0.091 \\
{[0.059]}\end{array}$ & $\begin{array}{l}0.143^{\star *} \\
{[0.070]}\end{array}$ & $\begin{array}{l}0.097^{\star} \\
{[0.054]}\end{array}$ & $\begin{array}{c}0.093 \\
{[0.067]}\end{array}$ & $\begin{array}{c}0.085 \\
{[0.088]}\end{array}$ \\
\hline (4) & $\begin{array}{l}\text { Bachelor's } \\
\text { Associate's from: }\end{array}$ & $\begin{array}{l}0.245^{\star * *} \\
{[0.066]}\end{array}$ & $\begin{array}{l}0.203^{* * *} \\
{[0.063]}\end{array}$ & $\begin{array}{l}0.536^{\star} \\
{[0.291]}\end{array}$ & $\begin{array}{l}0.220 * * * \\
{[0.073]}\end{array}$ & $\begin{array}{l}0.197^{* *} \\
{[0.080]}\end{array}$ & $\begin{array}{c}0.549 * * * \\
{[0.179]}\end{array}$ \\
\hline (5) & For-Profit & $\begin{array}{c}0.066 \\
{[0.091]}\end{array}$ & $\begin{array}{c}-0.027 \\
{[0.091]}\end{array}$ & $\begin{array}{c}0.209 \\
{[0.186]}\end{array}$ & $\begin{array}{c}0.071 \\
{[0.095]}\end{array}$ & $\begin{array}{l}-0.041 \\
{[0.099]}\end{array}$ & $\begin{array}{c}0.213 \\
{[0.180]}\end{array}$ \\
\hline & Bachelor's from: & & & & & & \\
\hline (6) & For-Profit & $\begin{array}{c}-0.082 \\
{[0.110]}\end{array}$ & $\begin{array}{c}-0.146 \\
{[0.117]}\end{array}$ & $\begin{array}{c}0.133 \\
{[0.431]}\end{array}$ & $\begin{array}{c}-0.084 \\
{[0.113]}\end{array}$ & $\begin{array}{l}-0.157 \\
{[0.128]}\end{array}$ & $\begin{array}{c}0.046 \\
{[0.392]}\end{array}$ \\
\hline (7) & Combination (3) + (5) & $\begin{array}{c}0.176^{\star *} \\
{[.083]}\end{array}$ & $\begin{array}{l}0.064 \\
{[.075]}\end{array}$ & $\begin{array}{c}0.352^{* *} \\
{[.171]}\end{array}$ & $\begin{array}{c}0.168^{* *} \\
{[.084]}\end{array}$ & $\begin{array}{l}0.052 \\
{[.083]}\end{array}$ & $\begin{array}{l}0.298^{\star} \\
{[.153]}\end{array}$ \\
\hline & $\mathrm{N}$ & 1900 & 1430 & 460 & 1420 & 1060 & 360 \\
\hline
\end{tabular}

The basic specification weights the observations by the sampling weights of the survey, while the Propensity Score specification weights the observations by propensity scores and sampling weights. Explanatory variables include: age, household size (parental for dependent students, respondent for independent students), income in 2002 (parental for dependent students, respondent for independent students), income in 2002*dependent, \# dependent children in 2003, expected family contribution to college finances in 2003, years delayed enrollment in college after high school, indicators for HS diploma, GED, dependent in 2003, parents born in the United States, Black, Hispanic, male, English is primary language, married in 2003, born in the United States, and parents having at most 12 years of education. For those under 24 in 2003, we have indicators for high school GPA above 3.0, took the SAT or ACT, and SAT/ACT score (included in 1st column just for those under 24, and the 3rd column). Each column includes controls for highest degree certificate, Associate's, Bachelor's, and interactions of each with for-profit

Degree institution types pertain to the highest degree obtained. 
Table 4: Impact of For Profit Colleges on Log Income, 2009 with Controls for Major: Start in Certificate Program, All Ages

\begin{tabular}{|c|c|c|c|c|c|c|}
\hline & (1) & (2) & (3) & (4) & (5) & (6) \\
\hline & \multicolumn{3}{|c|}{ OLS } & \multicolumn{3}{|c|}{$\begin{array}{c}\text { Propensity Score } \\
\text { Weighting }\end{array}$} \\
\hline Start Program at: & & & & & & \\
\hline (1) For-Profit & $\begin{array}{l}-0.048 \\
{[0.067]}\end{array}$ & $\begin{array}{l}-0.012 \\
{[0.067]}\end{array}$ & $\begin{array}{c}-0.014 \\
{[0.063]}\end{array}$ & $\begin{array}{l}-0.067 \\
{[0.070]}\end{array}$ & $\begin{array}{c}-0.027 \\
{[0.069]}\end{array}$ & $\begin{array}{l}-0.014 \\
{[0.066]}\end{array}$ \\
\hline Highest Degree: & & & & & & \\
\hline (2) Certificate & $\begin{array}{c}0.043 \\
{[0.059]}\end{array}$ & $\begin{array}{c}0.017 \\
{[0.055]}\end{array}$ & & $\begin{array}{c}0.012 \\
{[0.058]}\end{array}$ & $\begin{array}{l}-0.006 \\
{[0.055]}\end{array}$ & \\
\hline Certificate from: & & & & & & \\
\hline (3) For-Profit & $\begin{array}{l}-0.098 \\
{[0.090]}\end{array}$ & $\begin{array}{c}-0.092 \\
{[0.088]}\end{array}$ & $\begin{array}{c}-0.068 \\
{[0.084]}\end{array}$ & $\begin{array}{l}-0.062 \\
{[0.091]}\end{array}$ & $\begin{array}{c}-0.062 \\
{[0.088]}\end{array}$ & $\begin{array}{l}-0.067 \\
{[0.089]}\end{array}$ \\
\hline (4) Combination (2) + (3) & $\begin{array}{l}-0.055 \\
{[.070]}\end{array}$ & $\begin{array}{l}-0.075 \\
{[.070]}\end{array}$ & & $\begin{array}{l}-0.049 \\
{[.071]}\end{array}$ & $\begin{array}{l}-0.068 \\
{[.071]}\end{array}$ & \\
\hline Certificate with major: & & & & & & \\
\hline (5) Business & & & $\begin{array}{c}-0.161 \\
{[0.113]}\end{array}$ & & & $\begin{array}{c}-0.215^{\star} \\
{[0.126]}\end{array}$ \\
\hline (6) Vocational & & & $\begin{array}{c}0.170^{\star} \\
{[0.096]}\end{array}$ & & & $\begin{array}{c}0.119 \\
{[0.098]}\end{array}$ \\
\hline (7) Human Services & & & $\begin{array}{l}-0.046 \\
{[0.127]}\end{array}$ & & & $\begin{array}{l}-0.025 \\
{[0.127]}\end{array}$ \\
\hline (8) LPN & & & $\begin{array}{c}0.170 \\
{[0.134]}\end{array}$ & & & $\begin{array}{c}0.184 \\
{[0.124]}\end{array}$ \\
\hline (9) Health Administration & & & $\begin{array}{c}0.006 \\
{[0.095]}\end{array}$ & & & $\begin{array}{l}-0.030 \\
{[0.098]}\end{array}$ \\
\hline (10) Allied Health-Assisting & & & $\begin{array}{c}-0.024 \\
{[0.093]}\end{array}$ & & & $\begin{array}{l}-0.023 \\
{[0.089]}\end{array}$ \\
\hline (11) Health (Survey) & & & $\begin{array}{l}0.044 \\
{[.130]}\end{array}$ & & & $\begin{array}{l}0.116 \\
{[.127]}\end{array}$ \\
\hline Control for Major & $\mathrm{N}$ & $\mathrm{Y}$ & $\mathrm{Y}$ & $\mathrm{N}$ & $\mathrm{Y}$ & $\mathrm{Y}$ \\
\hline $\mathrm{N}$ & 1370 & 1370 & 1370 & 1260 & 1260 & 1260 \\
\hline
\end{tabular}

The basic specification weights the observations by the sampling weights of the survey, while the Propensity Score specification weights the observations by propensity scores and sampling weights. Explanatory variables are the same as those listed in Table 3 . Degree institution types pertain to the highest degree obtained. Columns (1), (2), (4), and (5) include controls for highest degree certificate, Associate's, Bachelor's, and interactions of each with for-profit. Columns (2) and (4) include linear controls for each major. Columns (3) and (6) include linear controls for each major, and interact each major with certificate, Associate's, and Bachelor's. The latter three variables are additionally interacted with for-profit. The returns to certificates by major are shown in the table only for majors where at least 30 students obtained a certificate in the OLS sample. 
Table 5: Impact of For Profit Colleges on Log Income, 2009 with Controls for Major: Start in Associate's Degree Program, All Ages

(1)

(2)

(3)

(4)

(5)

(6)

OLS Weighting

\section{Start Program at:}

(1) For-Profit

Highest Degree:

(2) Certificate

(3) Associate's

(4) Bachelor's

Associate's from:

(5) For-Profit

Bachelor's from:

(7) For-Profit

(8) Combination (3) + (5)

Associate's with major:

(9) Business

(10) Vocational fields

(11) Liberal Arts and Sciences

(12) Human Services

(13) RN

(14) Allied Health-Assisting

(15) Allied Health-Treatment

$\begin{array}{cc}-0.123 & -0.106 \\ {[0.076]} & {[0.070]} \\ & \\ 0.295^{\star \star} & 0.313^{\star \star} \\ {[0.120]} & {[0.136]} \\ 0.110^{\star \star} & 0.073 \\ {[0.047]} & {[0.047]} \\ 0.245^{\star \star \star} & 0.236^{\star \star \star} \\ {[0.066]} & {[0.066]}\end{array}$

$-0.108$

[0.077]

$-0.149 * \star$

[0.072]

$-0.127^{*}$

[0.071]

$-0.140^{*}$

[0.075]

$0.292^{\star \star \star} \quad 0.240^{\star \star \star}$

[0.096] [0.087]

$0.097^{\star} \quad 0.068$

[0.054] [0.056]

$0.220^{\star \star \star} \quad 0.195^{\star \star \star}$

[0.073] [0.070]

$\begin{array}{cccccc}0.066 & 0.064 & 0.072 & 0.071 & 0.066 & 0.075 \\ {[0.091]} & {[0.093]} & {[0.107]} & {[0.095]} & {[0.102]} & {[0.110]} \\ & & & & & \\ -0.082 & -0.119 & -0.176 & -0.084 & -0.113 & -0.116 \\ {[0.110]} & {[0.105]} & {[0.128]} & {[0.113]} & {[0.115]} & {[0.121]} \\ 0.176^{\star \star} & 0.137 & & 0.168^{\star \star} & 0.135 & \\ {[.083]} & {[.086]} & & {[.084]} & {[.090]} & \end{array}$

0.159 *

$0.157^{*}$

[0.096]

[0.093]

$-0.017$

0.029

[0.139]

[0.137]

$-0.009$

0.052

[0.070]

[0.086]

0.073

0.117

[0.096]

[0.111]

$0.482^{\star \star \star}$

$0.393^{\text {** }}$

[0.138]

[0.150]

$0.272^{*}$

0.053

[0.161]

[0.188]

$0.522^{\star \star *}$

$0.423^{\star \star *}$

[0.147]

[0.135]

\begin{tabular}{lcccccc}
\hline Controls for Major & $\mathrm{N}$ & $\mathrm{Y}$ & $\mathrm{Y}$ & $\mathrm{N}$ & $\mathrm{Y}$ & $\mathrm{Y}$ \\
\hline $\mathrm{N}$ & 1900 & 1900 & 1900 & 1420 & 1420 & 1420 \\
\hline
\end{tabular}

The basic specification weights the observations by the sampling weights of the survey, while the Propensity Score specification weights the observations by propensity scores and sampling weights. Explanatory variables are the same as those listed in Table 3 . Degree institution types pertain to the highest degree obtained. Columns (1), (2), (4), and (5) include controls for highest degree certificate, Associate's, Bachelor's, and interactions of each with for-profit. Columns (2) and (4) include linear controls for each major. Columns (3) and (6) include linear controls for each major, and interact each major with certificate, Associate's, and Bachelor's. The latter three variables are additionally interacted with for-profit. The returns to Associate's degrees by major are shown in the table only for majors where at least 30 students obtained an Associate's degree in the OLS sample. 